\title{
To the End Game and Beyond
}

[Institute and Faculty of Actuaries, Sessional Webinar, Monday 11 January 2021]

The Moderator (Mrs L. Evans, F.I.A.): Hello and welcome everyone to our sessional webinar today, "To the End Game and Beyond." I am pleased to welcome you all and to welcome members from all around the world. My name is Leah Evans and I am the Deputy Chair of the Pensions Board here at the IFoA, and also an actuary at Mercer, specialising in risk transfer and pension risk management. I will keep my introduction to this topic brief because I know the speakers have a lot to say, but suffice to say we all know that this is a huge topic. We have massive numbers of schemes that will have to be run off over the next few years, and although lots of us are spending a lot of time with our clients talking about this, there is still no firm industry consensus on what the best solution is, or how we help clients decide. And so, I really welcome the work that this working party has put together, and this comprehensive report with a really good summary of the current position and some useful suggestions.

Before I hand over, I just want to introduce today's speakers, who are a subset of the working party. Firstly, Costas Yiasoumi. Costas has extensive experience across both pensions consulting and working in insurers offering bulk annuities and longevity swaps to pension schemes. He is the chair of this working party and has also previously chaired the Running Off Mature Schemes Working Party and the IFoA Bulk Annuity and Longevity Swaps Member Interest Group and has also been a member of other working parties.

Jane Kola is a lawyer and has almost 30 years' experience advising trustees and employers on their workplace pension arrangements. Jane helps clients understand their risks and how to manage and mitigate these, finding practical ways forward. We are really pleased to have non-actuarial input into this working party and the presentation today.

Nigel Jones has been in the pensions industry for around 25 years and is currently Head of Pensions Advisory at Broadstone. He has also sat on a number of working parties for the IFoA.

Dweenisha Caleechurn is an actuary in EY's pensions consulting team and works across all aspects of pension risk transfer. She has been heavily involved in building EY's solutions in this area and has advised on pension schemes of all sizes.

Adolfo Aponte is a Managing Director at Lincoln Pensions where he advises trustees, corporates and financial institutions on covenant matters, including corporation transactions and funding de-risking structures. He leads Lincoln's covenant risk transfer team.

Rhian Littlewood is a qualified actuary with 10 years' experience in the pensions industry, mostly spent as a consultant advising pension schemes on all aspects of their end game journey. Rhian has recently moved into the insurance world and now works for Phoenix Life.

Kevin Wesbroom is a Professional Trustee with Capital Cranfield, having been a consulting actuary with Aon for over 40 years. He has been involved with many different strands of pensions, investments and broader employee benefits.

Dan Mikulskis is an investment partner at LCP. He is a lead investment advisor to institutions like pension funds, wealth managers and severance funds.

The team will have around 50 minutes of presentation and discussion between the panel, before opening up to questions from the wider audience. I would now like to hand over to Costas (Yiasoumi) who will lead us through the paper, with help from the team. Thank you.

\footnotetext{
() Institute and Faculty of Actuaries 2021. This is an Open Access article, distributed under the terms of the Creative Commons Attribution licence (http://creativecommons.org/licenses/by/4.0/), which permits unrestricted re-use, distribution, and reproduction in any medium, provided the original work is properly cited.
} 
Mr C. A. Yiasoumi, F.I.A.: Thanks Leah (Evans) and good afternoon everybody. I am going to steer us through the presentation with help from the co-authors. This is the point from which the working party started:

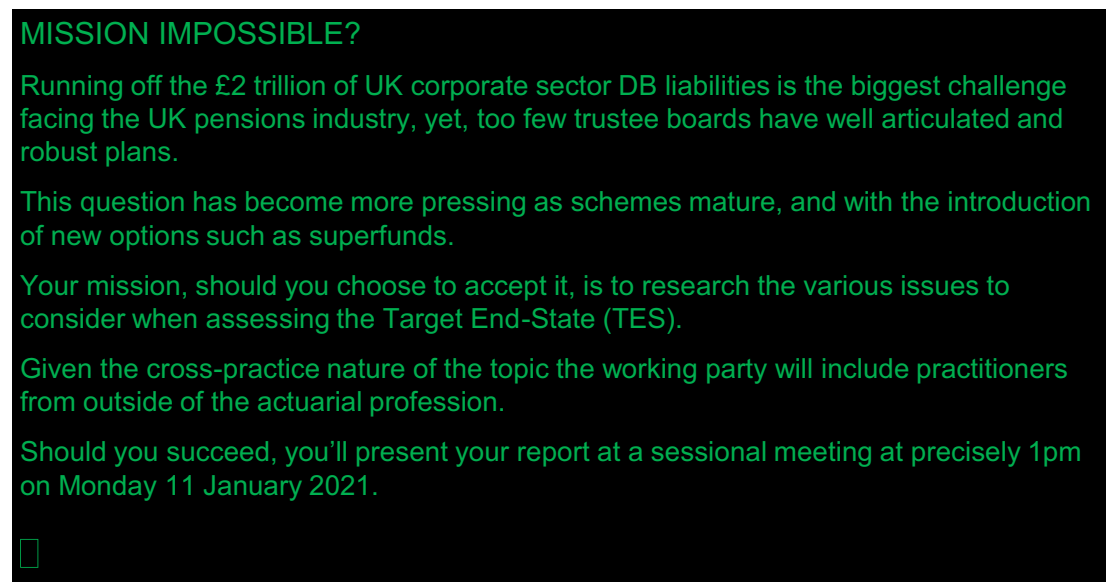

The "Mission Impossible" heading here highlights the fact that end game planning is such a huge topic that there was always the risk of the working party struggling to get to a conclusion. The backdrop was that, as a profession, we needed to do extra thinking to help advise actuaries guide their pension clients to a suitable Target End-State (TES).

Today we will:

1. Overview the paper and recommendations (50 minutes) - please ask questions!

2. Address further questions.

3. Hear your comments

Given the multi-disciplinary nature of the topic, it was essential that non-actuaries were involved. So, we were delighted that the working party included individuals with legal, corporate finance, covenant and trustee backgrounds as well as actuaries from across pensions, investments and insurance. What we will talk about today is the framework we have developed and the Target End-States that can be applied, in practice, to real cases.

\section{What do we mean by a Target End-State (TES)?}

The TES is the target stable state for a scheme such that when it achieves that state (providing it maintains it) member benefit entitlements will be met in full, with a high degree of certainty.

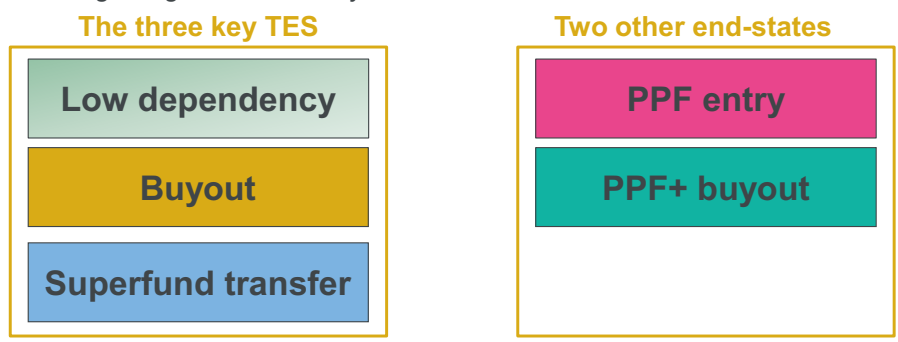


Let us start the discussion by defining what we mean by Target End-State. After all, if you are not crystal clear about your destination, you may end up somewhere completely different. Kevin (Wesbroom) will now explain why we, as a working party, settled on Target End-State rather than other phrases like "endgame"?

Mr K. R. Wesbroom, F.I.A.: There are two parts to that. Obviously, we know that we have passed the magic 50\% tipping point now for UK private sector DB schemes. Over half of them are now closed to future accrual. We are in the running off phase of the UK Defined Benefit (DB) pension system. I think the "target" part is interesting, because a lot of schemes know that they are doing something like this, but they have not formally adopted it as a target. The idea of a target is focused on carrying out an intention, a purpose. What we are trying to convey here is that, increasingly, schemes will have to start to crystallise their definitions of what they are trying to achieve, whether it is the three on the left-hand side of the slide or the two on the right-hand side. They will have to be more specific, more definitive about the whole process that they are trying to target and have much more certainty around it.

Mr Yiasoumi: For buyout and superfund end-states, quite frankly, I would say that they are end games because once you execute them, you are finished. The low-dependency one is different, so can you talk a little bit about that one? It seems to be a continuum rather than an actual end.

Mr Wesbroom: Yes. It may well not be an ultimate end-state in that sense. It is not a transaction; it is an ongoing process - you will run the scheme on. This is the state formerly known as self-sufficiency or by various other labels: low dependency, low reliance. One of the key things that we have discovered as a working party is just how vague this phrase was. If you asked people what it meant in terms of a funding target, this could range from (gilts minus $1 \%$ pa) up to (gilts plus $1 \%$ pa) or even (gilts plus $1.5 \%$ pa). It is pretty badly defined and that is one of the key things we are trying to encourage people to think about. If you commit to low dependency, what exactly do you mean? What are your funding targets? What is your investment philosophy? What residual risks are you going to be running and how are you going to address those? So, it is conceptually different to the others. It may be a stepping stone as well. It may be that you are in low dependency, but an opportunity for buyout or superfund transfer comes up, and you switch your Target End-State. To that extent, you are right Costas - it is a different position to the other two.

Mr Yiasoumi: We will come back to that later. Does buyout always give the best member outcome?

Mr Wesbroom: That is a leading question. This almost summarises the whole of the work of the working party. If you are in buyout, or if you are going to get to buyout, you could argue that you have delivered the members' benefits with $100 \%$ certainty. We can have a discussion about whether the insurance regime could collapse, whether the Financial Services Compensation Scheme would not pay out in full and so on; but for practical purposes, if you are in buyout, you are $100 \%$ certain of delivering members' benefits, which I think is the definition of success. The challenge is can you get to buyout before some of these other things happen to you?

Mr Yiasoumi: As a working party, every time we discussed end-state, we always came back to the same things. One of those was the legal obligations of trustees. We felt we had no choice but to address the legal aspects at the start of the paper.

Jane (Kola), The Pensions Regulator (TPR) publication last year said the following: "The Pension Protection Fund (PPF)'s experience is that scheme benefits are usually incorrect and the necessary work to put them right, more often than not, results in an increase in liabilities." Is the PPF being harsh on pension trustees here?

Ms J. Kola: I do not think it is being harsh, Costas (Yiasoumi). I think the experience we have is that trustees have, over the last 20 years, not invested in what their liabilities really are. They have relied very heavily on the administration and the systems delivering the right benefits without a 


\section{Putting the legal requirements at the start}

The duties placed on trustees are at the heart of all actions and decisions
Act in accordance with their legal powers
Pay the benefits to which the members and their beneficiaries are entitled
Act in the best interests of all of the scheme beneficiaries
Act impartially between members - no obligation to treat all the same way
Invest the assets in a manner which is appropriate

basis for knowing that it is correct. This is common across all schemes. I suppose the schemes which go to PPF are the ones that often have struggled the most with their budgets to invest in their schemes because of their sponsor situation. But I think most schemes do not have a benefit specification that a lawyer has looked at or, if they do, they only have it because they are about to go into the insurance market to do a buyout, not because they feel they need to look at it before then.

Mr Yiasoumi: So, PPF was not being harsh. To build on the question I asked Kevin (Wesbroom) earlier, we discussed whether buyout must be the target. Are trustees obliged to target that? If the answer to that was yes, our working party paper would be very different. It would be more about how trustees can achieve buyout. But I understand there is nothing in legislation that says buyout must be targeted. Is that true? Are trustees obliged to minimise risks or do they actually have quite an open piece of paper there?

Ms Kola: The legislation does not require the trustees to have any targets beyond getting to their technical provisions basis for funding purposes, which we all know is not buyout unless the trustees have the agreement, usually of the employer, to achieve that. So, there is no statutory requirement to get to buyout. Something else that is not well understood is that trustees are allowed to take legal risk in terms of determining what they are going to achieve, just as they take risk in other areas. So, it is more about trustees understanding consciously the risk that they are taking and then making conscious decisions, having balanced the issues, rather than walking into risks and then having to firefight to deal with them. Trustees who have thought about where they want to go, what is in their members' interests and what their sponsor can afford to do are the ones that have a plan that looks at the contingencies, looks at the risks they are running and then manages those over a number of years, rather than responding to events, which is quite often what trustees do.

Mr Yiasoumi: So, trustees need to think quite carefully about what their rules, say, what members will get from the scheme, and then decide on the target. Another party in this is the employer. Is there an example you can share of where specific powers of an employer can impact the Target End-State?

Ms Kola: The key one is, in most schemes, that the employer decides who the trustees are. Whilst an employer cannot appoint trustees to do its bidding, it certainly can appoint trustees who act properly whilst also having a similar view of the world to the employer. If the scheme 
is in a low-dependency world, that is perfectly legitimate. The other angle is that, even if the trustees really want to get to buyout, they cannot force an employer to pay the contributions necessary to do that. They must agree contributions in the statutory regime. That, too, can influence the position because if you cannot get the money then, by definition, you are going to have to invest your way there.

Mr Yiasoumi: Given what you have said and all the analysis we did on the legal side as a working party, do all trustees have a balance of powers paper on their desk from their scheme lawyer? This seems essential to me.

Ms Kola: Some schemes do, although it is usually very high-level and has very little to do with the benefits that are payable. I would say the majority do not have it, just as they do not have a legally signed-off benefit specification either that says what benefits are due. Most do not have discretion policies, so they are not actually entirely sure who agrees to what discretions. They tend to do things on a hit-and-miss basis. To be fair, there are some schemes that are incredibly organised and have all these things. However, the majority are not there yet, in my experience.

Mr Yiasoumi: Let's now move on to covenants. The concept of covenant was introduced by TPR some time ago. Most of us will be familiar with putting sponsors into one of the four covenant groups (CG), CG1 being the best and CG4 the worst. One of the things that struck me is that, regardless of how well funded the scheme is, it depends on covenant. Even a scheme that is $100 \%$ funded on buyout depends on covenant. Adolfo (Aponte) can you explain why covenant buys time?

\section{Covenant is not just about the money}

1. The underwriter of investment, funding and demographic risks

2. A source of additional funding for a scheme

3. A key factor determining the time a scheme has to realise its TES

Time is a valuable commodity. For a scheme in
low dependency, it might be the most valuable
(and in some cases only) benefit of the covenant

Mr A. Aponte: Certainly. As you point out, the industry, since the 2004 Pensions Act, has focused quite heavily on ratings which provide view on the ability of the covenant to underwrite funding and investment risk as well as its ability to provide cash flow to the scheme where a deficit is identified. Less focus, however, has been put on how covenant should influence it has with the trustees' end game strategic objectives. The reality is that, as we found out as a working group, covenant should have a material impact on the end game strategy that trustees put in place. For most schemes, this means that if their employer fails, they will face one of three options. Option (1) is being forced to go into an insurance contract. If funding levels are above the buyout requirement, then all benefits are covered. The other two options, which are probably the two options that are most relevant to pension schemes in the UK right now, are (2) getting into PPF plus territory, that is, not having sufficient funding to cover all benefits, but having sufficient funding within the scheme to cover benefits in advance of, or in excess of, the PPF; (3) entering the PPF. Importantly, a lot of schemes have focused on improving their funding position and de-risking their investment strategy, but if their employer fails along the way of delivering their objectives then the scheme could be facing one of these last two options. 
Mr Yiasoumi: What you are saying is that most schemes that have a reasonable funding level, given enough time, can invest their way out and deliver member benefits in full, regardless of whether or not they get additional funding from the employer. However, if the employer becomes insolvent, that calls time. You are no longer on a long-term journey. You have then got a shortterm horizon and you fall into one of those three options.

Mr Aponte: That's exactly it, Costas (Yiasoumi). The reality is that, regardless of how well funded the scheme is, in most cases the force impacting the employer will be independent of the pension scheme. So, for those schemes that have a weak employer and are looking to rely on that employer for 5 or 10 years, there is a non-negligible risk of that employer getting into some level of distress over that period of time.

Mr Yiasoumi: We will come back to it later, but I have seen plenty of other work that basically points out that there are a huge number of schemes, a thousand or more, that will never make it. Their employer will become insolvent before they can secure members' benefits in full. So this is not a trivial issue.

Mr Aponte: That's it and we are seeing it play out in the headlines of the national press in recent years. Given the economic reality we are living through right now, we expect the number of covenant failures to increase. I think it is a very relevant topic for trustees.

Mr Yiasoumi: Let's move on then to thinking about the Target End-State. Dan (Mikulskis), the phrase "Long-term objective" has already been coined. So, why didn't we simply use that as a working party and why have we come up with our own term, "Target End-State"?

\author{
A TES should be properly defined \\ 1. Is the definition tangible? \\ 2. Is it specific enough to help decision making? \\ 3. Is it clear and unambiguous (or is it open to interpretation)? \\ 4. Is it outcome focused (or funding focused)? \\ 5. Is it prescriptive in terms of investment policy? \\ 6. Is it objectively measurable?
}

Mr D. P. Mikulskis, F.I.A.: What we realised is that the words and phrases that you use do matter. They influence how you frame things and how you think about things. But we do have to be pragmatic. As actuaries, we love to redefine everything, but that isn't always helpful. I remember the conversations we had. We weighed terms case by case. Is there a strong enough case for introducing a new name for this item? If not, let us align with what is being used. And here we did think there was as a case for changing the term, and that is for a few reasons. We wrestled with the idea of buyouts, consolidation and low dependency as three things that are distinct. Two of them are a transaction that you hit, and you can say when you have done it, and the other one is much more of an ongoing state. That was one issue. Another one is that the Target End-State, we felt, was of a higher order that sat above the objective. The objective could be something to do with funding or investment, but the actual state you are in sits above that and incorporates the objective within it. A lot of the discourse is focused purely on funding objectives. Objectives are an important component of a Target End-State but do not come anywhere near describing the fullness of it. Those were the reasons we decided to introduce something new here. 
Mr Yiasoumi: Yes, and I like the six criteria in Figure 5 because they make it a lot more real. You know when you have arrived there. One of the challenges, for us, as an industry, is that trustees do not define very specific Target End-States. They tend to just define something very "woolly," which is not very helpful in terms of building journey plans or as a management tool.

Mr Mikulskis: Yes, that is right. But importantly, I think things have got better. A few years ago, the targets were dominated by "paying the pensions when they fall due," which is the vaguest of all objectives. I think that has been replaced more and more with funding targets for the long term. That is great but, as we said, funding is just one part of it. Also, trustees are often reluctant to actually put a buyout target in writing, even if that is the real target.

Mr Yiasoumi: And one of the things the working party did, which we won't cover today in the interest of time, is to provide wording and context to help produce quite solid definitions of what the end-state is, regardless of the choice of end-state. Number five on the list is "prescriptive in terms of investment policy." What do you mean by that, Dan (Mikulskis)?

Mr Mikulskis: That one came from the fact that often, if you define something in terms of a funding objective, a lot of trustees will say "our long-term objective is to be fully funded on gilts plus 50 basis points." That is saying nothing at all, quite often, about what the investments are doing. An alternative way of thinking about it would be to say that the investments had to be in high-quality bonds. You are then being very prescriptive. So there is a question of how prescriptive you want to be on the investment side. It feels like your target ought to say something on investments, but then it's also possible that this could be well into the future, and so you do not necessarily want to pin yourself down to investing in a certain type of bond or similar. That is a real variable that I do not think is debated anywhere near as much as it could be.

Mr Yiasoumi: In simplistic terms, it is thinking about the investment side rather than starting from the discount rate and trying to fit an investment strategy around it.

Mr Mikulskis: Yes, this is the classic chicken and egg question. What comes first, the discount rate or the investment strategy? I am not sure what the answer to that is but, quite often, that is the thought process you go through. You think, "we are funding on gilts plus 50 basis points so what investment strategy do we need to back that?" Or, did that come out of the fact that someone had an investment strategy in mind and got the discount rate out of it? It is important to unpack this and get to the bottom of that little dilemma.

Mr Yiasoumi: Let's move on to low dependency. We have spent quite a lot of time on low dependency. It was the first of the end-states we considered, and there is a definition here from TPR. Just to challenge again why, for example, is "gilts plus 25 basis points" not good enough? Why did we draft pages and pages on low dependency?

\section{Low dependency - more than a discount rate}

\section{"Low dependency means that funding and investment strategies are such that there is a low chance of requiring further employer support and, to the extent that such support is required, it is low relative to the size of the scheme". [TPR 2020]}

We set out:

1. A strong form of low dependency

2. A probabilistic approach to low dependency

3. A qualitative (weak form) of low dependency ... and the key considerations for assessing these 
Mr Mikulskis: It is a good challenge and "gilts plus 25 basis points" would not be the worst starting place. However, as you have probably picked up from what I have already said, that definition is silent on a lot of really important things. From my perspective, as an investment consultant, it is silent on what the investment strategy ought to be. Based on industry surveys about $40 \%$ to $50 \%$ of all schemes are targeting this end-state, so this is highly relevant for a huge number of schemes. A lot of schemes are getting to the point where they are making decisions on investment strategy, and where they need to have a clearer idea of what that ultimate investment state needs to be. For example, presumably it is investing in bonds, but what kind of bonds? Do you want to sell all your equities and buy bonds or keep some equities? What about property? Do you allow global bonds? Do we allow high-yield bonds? How high quality do they have to be? Are we looking to match cash flows entirely or not? What about longevity? Are we assuming having a longevity swap or not having a longevity swap? You must ask yourself "what are we trying to achieve here?" and if your objective only says to be fully funded on gilts plus 25, you have not come close to answering any of those questions.

Mr Yiasoumi: So "low dependency" is describing, in effect, the whole scheme. What will it look like when we are in low dependency? There will be big ticket items like investments, but also for example what will the administration of the scheme look like? What might the trustee board look like? What risks have we hedged? What is our member options strategy? When you have a complete definition, you can work towards it.

Mr Mikulskis: Yes.

Mr Yiasoumi: Is it worth touching on one of those measures? In the paper, we have given three alternative forms of low dependency as a means of illustration. The probabilistic one, do you want to just say a few words on that?

Mr Mikulskis: Yes. I think this grew out of the fact that, traditionally, you could specify a funding target. You could then specify an investment strategy and the other items alongside that. Or you could step up a level and define the target in terms of delivering the pensions with $95 \%$ certainty. The nice thing about that is that it incorporates the joint funding and investment policy. So it allows for a range of investment strategies and/or funding policies but bringing them together gives you your $95 \%$ number. It is a nice way of bringing a lot of different variables together without having to define them all separately. There is a lot of modelling around the industry now that allows you to do that, albeit with disadvantages in terms of the complexity and assumptions that you have to make. It is also quite clear and quantifiable for trustees. So, there are some advantages and disadvantages to this approach, but we thought it was worth putting on the table.

Mr Yiasoumi: Yes, I really liked it. Rhian (Littlewood), you have recently moved to work at an insurer. If an insurer had to set a Target End-State, would it go about it in the same way as a pension scheme?

Ms R. Littlewood, F.I.A.: I think it would be a bit different, partly because insurers start from a completely different point. There is not really a concept of recovery plans in the insurance regime. I would say the way insurers tend to work is probably closest to the probabilistic approach to low dependency. I think the key point there is, like the point Kevin (Wesbroom) made earlier, that low dependency does not represent a firm end point. It is a state that you must stay in. Part of our recommendations is that schemes should do that. The other real difference in the insurance world is that insurers do not tend to hold the minimum required assets to meet these, whatever definition of low dependency they choose to use. There are always buffers and margins, which is something that pensions schemes perhaps do not do so much.

Mr Yiasoumi: Kevin (Wesbroom), who spoke earlier, was quoted as saying "there's nothing wrong with gilts, as long as you're prepared to vary the plus." Why are you going to stick with the old gilts plus some fixed number? Why don't actuaries look at what the scheme investments are telling them about what the plus ought to be, rather than apply the number you used at the last actuarial valuation? Dweenisha (Caleechurn), is there anything wrong with sticking to gilts plus a fixed percentage point? 


\title{
Are dynamic discount rates the answer?
}
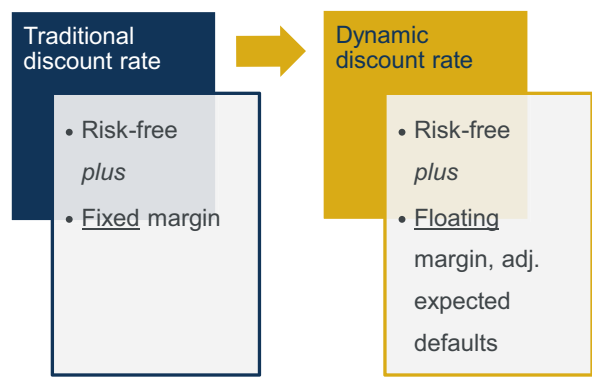

\author{
Based on a buy-and-hold investment \\ strategy where income matches \\ benefit outflows \\ Analogous to the approach insurers \\ utilise \\ "Floating margin" reduces funding \\ volatility \\ Could result in a (much) higher best \\ estimate discount rate than gilts plus \\ $50 \mathrm{bps}$
}

Ms D. D. Caleechurn, F.I.A.: In short, for low dependency, the answer is yes, and I will explain why. As Dan (Mikulskis) has already mentioned, historical common practice was to discount pension liabilities at, say, gilts plus a fixed margin, for example, Gilts plus 50 basis points. This meant that, as a scheme matured, the overall funding basis would just tend towards this figure. This was broadly consistent with an investment strategy of investing in those high-quality secure bonds, notionally or not. But in a low-dependency state, in particular, it is not just about the investment strategy. It is about the joint and more rounded view of how funding, covenant and investment strategies work together to deliver the member outcomes. Very importantly, at the same time, it is also about not creating excess funding level volatility. To achieve this, you could instead align the discount rate with the actual yield on the portfolio. This means moving to an approach, that is, gilts plus floating, as you mentioned, that is, gilts plus variable margin.

Mr Yiasoumi: What you are saying is, especially for schemes that hold some form of cash flowdriven investment (CDI) strategy, you can just get the yield achieved and that is your discount rate?

Ms Caleechurn: Yes. The floating or variable margin is adjusted dynamically to reflect the returns on the actual asset portfolio and so the dynamic discount rate changes over time, in line with the asset portfolio. As I mentioned, this results in a much smoother funding position through time, and less variability in the deficit reduction contributions that get paid. It helps you to more closely match assets and liabilities and removes the artificial funding volatilities that you may get otherwise.

Mr Yiasoumi: One of the questions that was asked by email in advance was about the variable discount rate, pointing out that the discount rate does not actually impact the liabilities. The answer is yes, the liability, as Jane (Kola) explained, is to pay the pension, but the fact is that in life what gets measured gets done. If you have artificial volatility in the funding level, then that can have impacts. Variable discount rates sound quite straightforward. I understand that for insurers, determining and maintaining a variable discount rate is a task for an army of actuaries. Is that true or can most pension schemes just adopt this type of approach if they see fit? Rhian?

Ms Littlewood: Yes. It is completely true that there is huge investment, expertise, manpower and resources that go into this, and insurers can generally afford to do that because they have got longer-term time horizons in many cases, because they are not looking to buy out in the future. They also have the buying power in terms of economies of scale to make sense of it. And so it is effective and it does result in a very stable solvency position when it is done properly, but I think the big question is about whether it is realistically within the reach of most pension schemes.

Mr Yiasoumi: If a scheme wants to adopt a variable discount, especially one that gave a discount higher than the ones under the proposed new funding code, TPR might be asking "what expertise are you applying here?" 
Let's move on to the first of our polls to get some reaction from the audience.

Poll 1

Actuaries should press trustee boards to take legal advice on their powers under their scheme rules and on the detailed benefit entitlements of members.

Results of Poll 1

Strongly Agree - actuaries should add strong qualifications to advice

$25 \%(46)$

where this hasn't been done

\begin{tabular}{lc} 
Agree & $66 \%(123)$ \\
Disagree & $8 \%(15)$ \\
\hline Strongly Disagree - this is the job of TPR & $1 \%(2)$ \\
\hline & Total votes 186
\end{tabular}

I am astounded at these results. I thought there would be many actuaries who would not be comfortable pushing trustee boards on this, but it seems to me that the consensus is that it is really important and actuaries should take leadership here. What is your perception?

Ms Kola: I think that actuaries do want to push for legal advice, but some of their clients push back pretty hard. Collectively, actuaries agree that generally there need to be collaboration in respect of benefits, and that more clients will accept that. So, I think it is useful to see the poll and the strength of views in respect of this.

Poll 1 (cont.)

The actuarial profession should sponsor research into using dynamic discount rates for technical provisions (this will become increasingly relevant for schemes with a low-dependency TES that adopt asset strategies that more closely address matching of assets and cash flow liabilities).

Results of Poll 1 (cont.)

\begin{tabular}{l|c} 
Strongly Agree & $23 \%(44)$ \\
\hline Agree & $58 \%(109)$ \\
\hline Disagree & $16 \%(30)$ \\
\hline Strongly Disagree & $3 \%(5)$ \\
\hline & Total votes 188 \\
\hline
\end{tabular}

Mr Yiasoumi: Looking at the poll results here, I think the consensus, again, is that we would welcome more work done in this area.

Let's get back into the presentation and talk about member outcomes. I remember the situation before the PPF was formed, when employers became insolvent. There were some really horrific stories of members losing all of their benefits just a few months before pension age. In that context, the PPF's been a great success. But Nigel (Jones), what does PPF entry mean for members?

Mr N. Jones, F.I.A.: I agree with you. I remember the time when members received very little of their benefits and there was nothing they could do about it. But if you look at Figure 8, the clear implication is that members will not receive full benefits under the PPF. The compensation percentage can range from as low as $40 \%$ of the expected benefit up to nearly $100 \%$. However, the outcome where pensions are reduced under the PPF is still likely to be considerably better than had the PPF not existed. So, remembering horror stories of the past, I think PPF entry could be viewed as a reasonable second prize. If I look at the pattern of the chart, though, under the PPF deferred members receive $90 \%$ of expected benefit, or expected pension, and pensioners receive $100 \%$ of expected pension. But more importantly, members also usually see lower than expected increases in the PPF, compared to their scheme benefit. And it is these two features, Costas 


\section{Vast range of member outcomes on PPF entry}

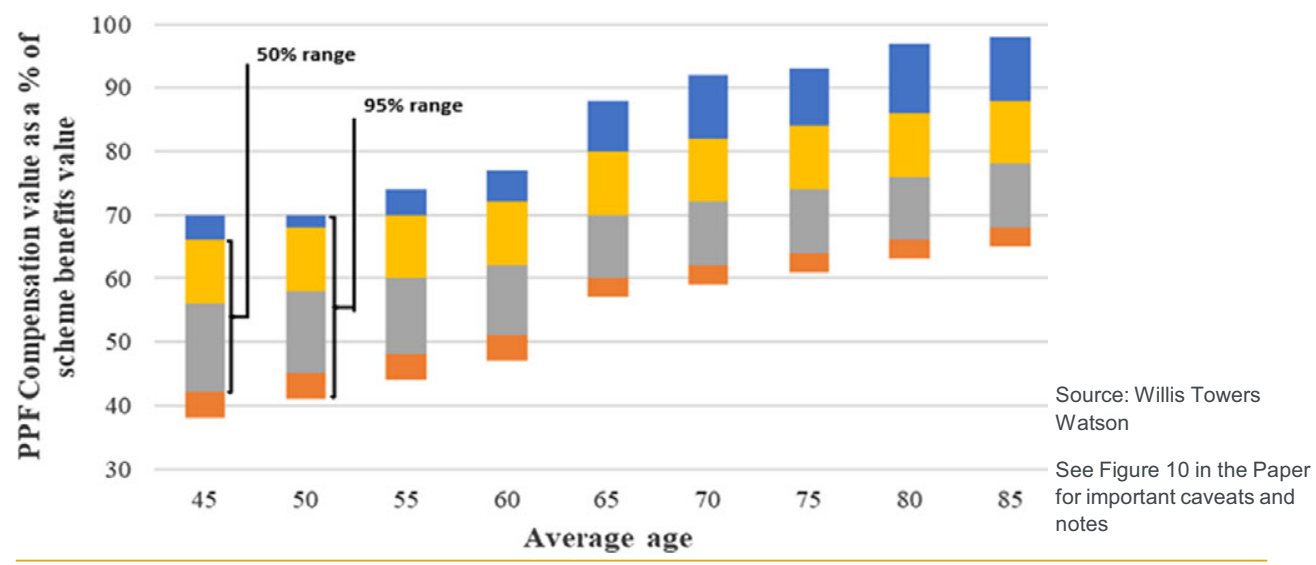

(Yiasoumi), that create the pattern in the chart. Quite simply, those at younger ages have longer exposure to PPF benefits and as these are lower than Scheme benefits we see a decreasing pattern with decreasing age.

Mr Yiasoumi: Is it possible to generalise? There is such a wide range of outcomes. Yes, older do better than younger, but it must be tough, as a trustee, to understand how your different member groups are going to be affected?

Mr Jones: Yes, I think it is possible to broadly generalise in the sense that the pattern does largely hold true. Those people at younger ages do worse as a rule, just because of their longer exposure to the PPF benefit. But if we look at the median value, it puts the member outcome at around $70 \%$ of expected value, and I think that is a good yardstick. Going back to one of the points Kevin (Wesbroom) made on buyout, if we ignore employer insolvency risk and the Financial Services Compensation Scheme (FSCS) and all those pieces, you could say that buyout value is $100 \%$ of expected value. The median value under the PPF is $70 \%$ and we can sensibly compare this to the $100 \%$ buyout value reference point. The value is obviously modified by scheme specifics and, most notably, scheme increases. You can see some large spreads at each age, because those schemes that pay the larger increases are the ones that are most affected, and you see a bigger member loss under the PPF. But I am comfortable with the general yardstick of $70 \%$ of expected value under the PPF, $100 \%$ for buyout and maybe something in the middle when we get into the other regimes.

Mr Yiasoumi: Let's move to superfunds on the next slide. It seems to me that where benefit cutbacks are a real possibility, trustees should be asking how they can get the best outcome for members, even if no outcome offers complete certainty. There are so many moving pieces for pension schemes. Any one of them can wobble or fall down and change the outlook for member outcome. Although it is possible to generalise, member outcomes are very member-specific. How can trustees decide what is in the best interest for their members?

Mr Jones: The answer is, as you may expect, that it is very difficult. There are lots of moving parts: buyout, covenant, legislation and other different factors. One of the things we have discussed as a working party is that it is really about the assessment of the member outcome with the information you have. The bottom of the slide sums this up well for me. It is all about member outcome. If you look at superfunds, for instance, they can rely on less capital than insurer buyouts. Scheme assets should go further, from a simplistic point of view, and one should be able to increase the likelihood of a higher benefit outcome for members, assuming full buyout is not affordable. So, back to the thinking of the previous slide. If the PPF delivered $70 \%$ of expected 


\section{Superfunds - should I stay or should II go?}

\section{Should I stay?}

Relatively weak covenant and a funding shortfall against buyout. If the members remain within the existing scheme they retain exposure to the covenant and if it fails they will likely receive reduced benefits

\section{Or should I go?}

If the scheme transfers to a superfund there remains a possibility of failure but it might be that that possibility is lower and it might be that the benefit cutbacks on failure are also lower

It is all about member outcomes. Superfunds do not need insurer like security so as to vastly improve member outcomes

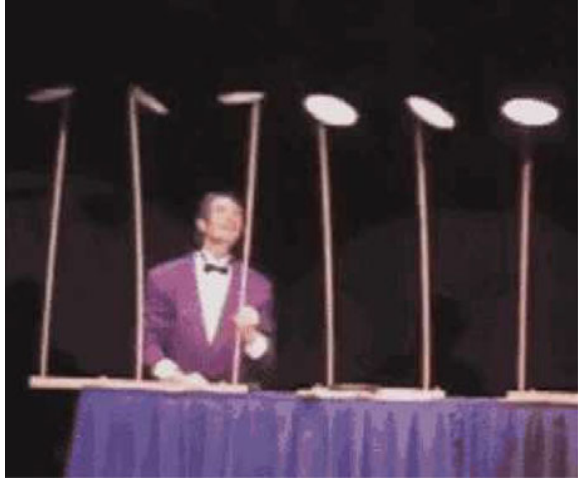

Source, tenor.com

benefit value and a buyout is $100 \%$ of benefit value, then one could expect a superfund to sit somewhere between these two values.

Mr Yiasoumi: Given these different possibilities, something we as a working party spent a lot of time on was member outcomes. We felt that in order to make informed decisions, these outcomes needed to be properly modelled. Although using experience and generalisation is very helpful, modelling member outcomes at a granular level gives extra insight and also allows easier communication and decision-making by trustees.

\section{Member outcomes - the race against time}

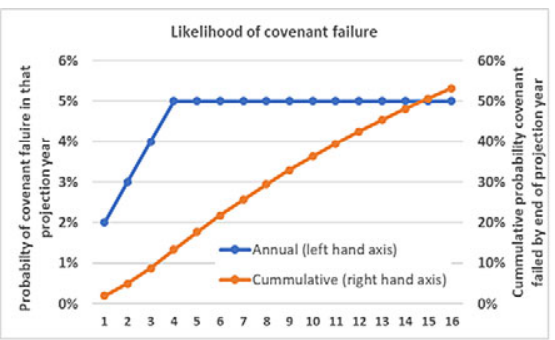

- A. Lower risk asset strategy

- B. Higher risk asset strategy (expected)

- C. Higher risk asset strategy (1/20 downside)

Deferred pensioner, large gap between scheme benefits and their PPF compensation level

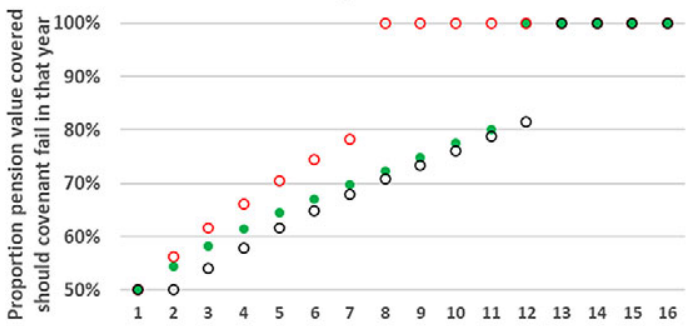

So, let me go through a couple of member outcome examples. The way to read this slide is as follows: on the left-hand side, if we look at the orange line, this shows the cumulative probability of an employer failing over future years; we have years on the $X$ axis; and the cumulative probability on the right-hand side $Y$ axis. This graph shows a cumulative probability of failure of $30 \%$ by year eight and $45 \%$ by year twelve. I think we can all agree that, in general, the better the funding level 
at the time of failure, the better for members. Now, let us look at the right-hand chart. Rather than focusing on funding levels, let us focus on the proportion of pensions secured for a specific deferred pensioner. The green dots show the proportion of pensions secured if a prudent investment strategy is adopted and the employer fails. We can see that, for this deferred pensioner, the proportion of pension secured increases from $50 \%$ to $60 \%$ by year four. That is a massive $20 \%$ pension improvement, and that is going to be far more than the average for the scheme. By year twelve, we get a sudden jump because the trustees here have decided to go to a superfund, but there is a $45 \%$ chance that the employers fail before they get to that position in year twelve. The red circles show the same deferred pensioner, but in the event of the trustees adopting a higher-risk and higher-return strategy. What we can see is that they achieve the superfund funding level by year eight, and there is only approximately a $30 \%$ likelihood of insolvency before then. The black circles show the one-in-twenty downside with the higher-risk investment strategy and we can see that for this member, the outcome is not actually that much worse than what the low, more prudent investment strategy would show. For this trustee board, we are not suggesting they adopt one investment strategy over another, but without looking at member outcomes for different, specific cohorts of members, it is very difficult to make an informed decision.

\section{Member outcomes - unexpected consequences of prudence}
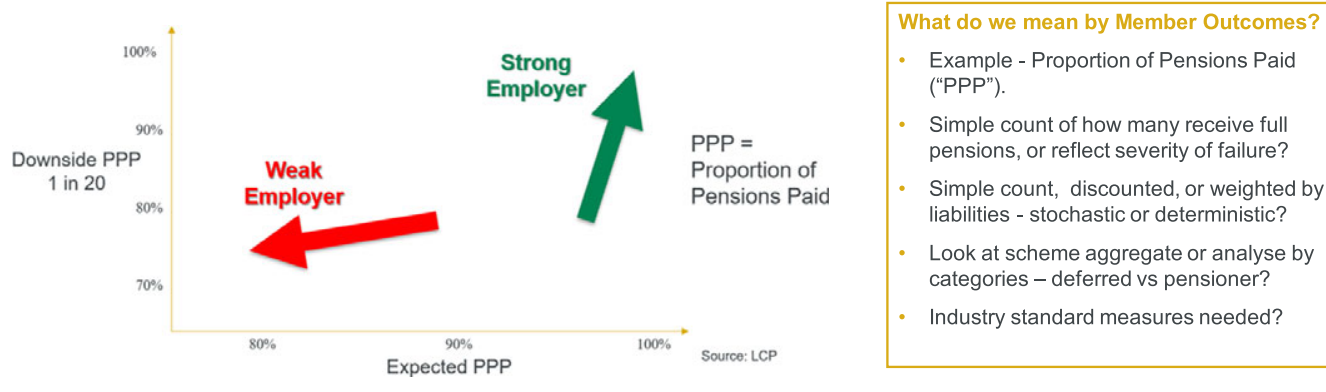

Our second example of member outcomes shows the expected proportion of pensions for two schemes, but with different employers. One has a strong employer, in other words a relatively low risk of insolvency. If the trustees make their investment strategy and funding basis more prudent, they get additional employer funding and, in the unlikely event of employer insolvency, the members are better off as the scheme is better funded. The position is different for the weaker employer. If those trustees adopt a more prudent approach, yes they will get additional funding but, in this case, the extra strain on the employer increases the probability of failure and, overall, members are worse off. Kevin (Wesbroom), given these sorts of member outcome examples, surely trustees have always considered member outcomes in some detail?

Mr Wesbroom: I think they have, Costas (Yiasoumi). But I think they have probably considered them at a generic or an implicit level. I think what these examples are starting to illustrate is that they need to get a lot more explicit and a lot more numeric about member outcomes. We would typically all applaud a lower-risk investment strategy. However, if all that does is increase the duration over which the scheme is exposed to sponsor failure and, using Nigel (Jones)'s numbers, instead of getting $100 \%$ of their benefits, members drop to getting $70 \%$ of their benefits, then 
overall it is probably not going to be in members' best interest. This is a very different sort of thinking, because it introduces explicitly this whole idea of long-term covenant.

Mr Yiasoumi: There are always going to be trade-offs in this sort of analysis, and I suppose there is a little bit of "damned if you do, damned if you don't" in some situations. It is a matter of looking at what is in the best interest of the members as a whole and recognising that some members may be impacted differently from others. But if we wanted to take these member outcomes to the next level, what type of modelling are we thinking of? What types of metrics?

Mr Wesbroom: Those would be the sorts of ideas that both Dan (Mikilskis) and Nigel (Jones) have been mentioning. That is, long-term stochastics. The key is now to explicitly include the possibility of failure of the sponsor. You put that into an asset-liability model, so you have assets, liabilities and covenant being run over a potentially quite long period of time. Then we can extract this key statistic of how many times or what proportion of times members' benefits get paid in full. We might get not just a simple count but the severity of failure. It does not matter if you have a failure, to be honest, if you only have a 99-year-old pensioner who's got most of his pensions and then misses out on 1 year of final pension. Let's put that into this metric of total proportion of pensions paid, "PPP." It could be very straightforward.

Mr Yiasoumi: It must be challenging. It will depend on the assumptions. I had a look at the work that was done. For example, the TPR has commissioned some work on superfunds.

Mr Wesbroom: You are right. You are highlighting some of the technicalities that we are going to have to get to grips with. If somebody turns up and says "my scheme has a Proportion of Pensions Paid of 96\%" then what do you do? Give them a pat on the back? Or say, "that is $4 \%$ failure, that's dreadful." As a group, we do not quite know where we should be or where we want to be or if moving from $90 \%$ to $91 \%$ is worthwhile. We have not got that confidence yet, as an industry, that we understand what these numbers are, let alone explain them to trustees and sponsors but also to members.

Mr Yiasoumi: We really need to get to that. In the example I gave earlier, the deferred pensioner saw a $20 \%$ increase in the pension they would get on employer insolvency over just 4 years. That is massive for them. Yet some of those older members, the 99-year-olds you mention, may see no increase in benefit, because they are no worse off or better off under the PPF.

Mr Wesbroom: Absolutely, you are quite right. You could take this analysis and then make it more granular. You could say, don't just work out a scheme score, but break it down into different cohorts and different groups of membership. However, as you alluded to, these are potentially quite difficult calculations we are getting into. Assumption-setting can also be difficult, a key set of which would be the insolvency probabilities. As actuaries, we could have a field day with working out what the probabilities are. We should be talking to people like the covenant advisors to help us in that regard. But we also need to recognise, when talking about $98 \%$ or $99 \%$, that these are the tails of distributions. These are not in the middle of a bell curve, but the extremities. Are you sure your calculations or your assumptions are robust enough here? I am not saying it is going to be easy, but I do think it is going to be necessary to give best advice to people in navigating their end-states.

Mr Yiasoumi: We will poll shortly on that. As a working party, we spent a lot of time figuring out how to bring together all the different components in a coherent way to derive a Target EndState and, in the end, we settled on this five-step process that we think can be applied to most situations. We are not claiming it is the only way, but it is a way. Importantly, in our view, as actuaries we are perfectly placed to act as a hub to help clients pull all of this together to develop their Target End-State.

Dweenisha (Caleechurn), in step one, we say that some Target End-States may not be in play. Can you give an example there?

Ms Caleechurn: Yes. Circumstances for different schemes, obviously, are very different. The obvious example I would give is for a buyout. They could be achieved in the short term for some schemes but not others, and it is important for trustees to have a realistic and robust journey plan. So, for example, a Target End-State of buyout in 40 years' time is not a very realistic plan. Equally, 


\section{The five steps to the TES}

\begin{tabular}{|c|c|}
\hline Step 1: & $\begin{array}{l}\text { Use a long term IRM framework to identify which of the trio of TES are in play } \\
\text { and the Journey Plans that would get the scheme to those TES. }\end{array}$ \\
\hline Step 2 & $\begin{array}{l}\text { Understand any requirements, constraints or other factors that may impact } \\
\text { the choice of TES. }\end{array}$ \\
\hline Step 3 & $\begin{array}{l}\text { Model for different Member Outcomes under the TES in play in the event of } \\
\text { the employer default. }\end{array}$ \\
\hline Step 4 & Eliminate any TES or Journey Plans that are not desirable. \\
\hline Step 5 & $\begin{array}{l}\text { Determine the preferred TES from those remaining, after which the Journey } \\
\text { Plan can be refined and a plan of action developed. }\end{array}$ \\
\hline
\end{tabular}

if you are targeting buyout in 5-10 years' time but the scheme is only $50 \%$ funded, this is not very credible or realistic either. Another point to make here is that a Target End-State need not be forever. It can be reviewed periodically and adapted and changed as circumstances change. In that sense, it is more like a staging post. It can be more than one journey plan or can contain options within that journey plan.

Mr Yiasoumi: In step two, are there any factors that might rule out certain Target End-States?

Ms Caleechrun: Yes. An obvious one is that the size of the scheme can restrict the solutions available to it. An example is longevity swaps. At present, as we know, these only really make sense for the largest schemes, say half a billion plus. That could be a constraint. Sometimes employers and trustees also have conflicting constraints to consider, for example, the accounting impact of a buyout. Would a buyout lead to an impact on the Statement of Other Comprehensive Income (OCI) or Profit and Loss Statement (P\&L)? This is more of an employer consideration. However, for the trustees, this is not high up on their agenda, if at all. They will be more concerned about covenant.

Mr Yiasoumi: So, a mix of considerations. For the small schemes, the scheme may never have enough economic resources for a low-dependency state. That is step one. Step two might be that the employer may see some quite material impact on its financial statements at buyout, which might mean the timing of buyout is impacted, or it might even mean buyout is not a realistic option. I guess that is just something to work with the client on. When you work through all of this, you get to step five. Would you expect to see a unique and best Target End-State? Or are trustees going to have to take a view and decide on an option without knowing if it's the best one?

Ms Caleechurn: It is actually a mixture. You could very well end up with more than one Target End-State and more than one journey plan at play in step five. This is where the trustees, with the help of their advisors, actuaries, covenant, investment specialists, perhaps even legal advisors, would need to consider which one to select. There will be trade-offs, but the most important point here is that these are made on an informed basis, so it needs to be a rationally derived Target EndState. A key leitmotif is the theme of member outcomes, keeping member benefits at the heart of the decision-making process. Also, as I said, the decision does not need to be that ultimate, final state; it can be just a stop in what might be a multiple-stop journey, and you could perfectly well end up with a Plan A and a -Plan B as well.

Mr Yiasoumi: You have given an excellent cue on to the next slide, which is about Plan B. We have already mentioned that things can go wrong for a pension scheme. They might not go according to plan and, consequently, there is no point focusing only on one plan. What do we mean by Plan B? 


\section{Developing a scheme's Plan B is essential}

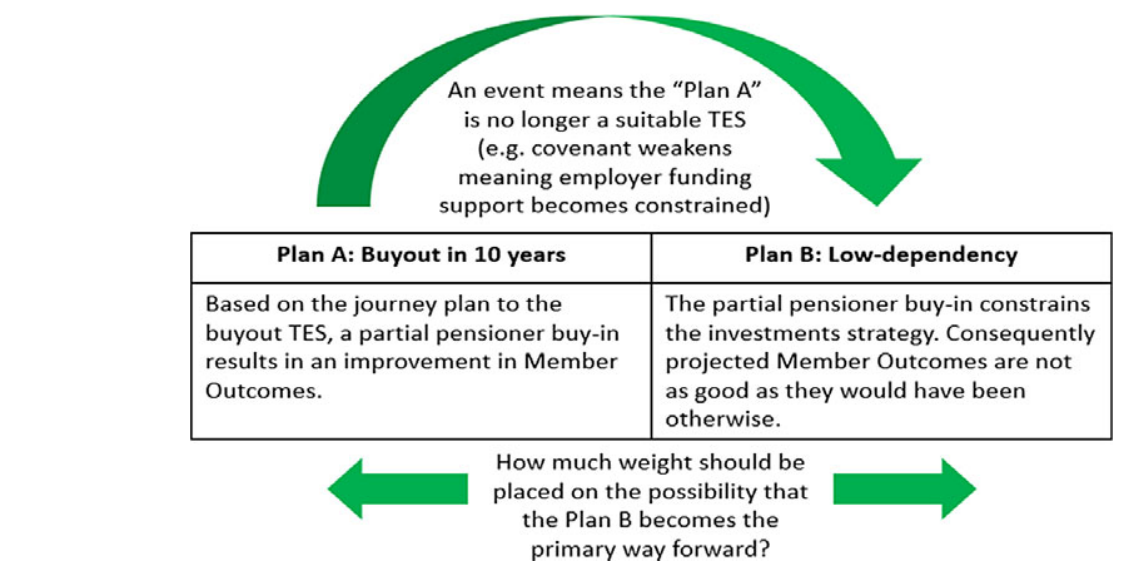

Ms Caleechurn: Plan B is a back-up plan or contingency plan. The current COVID-19 situation is a very relevant example of how even very well-developed plans can be thrown off course. It highlights the need to consider other potential scenarios that might vary from the expected course you have charted out.

Mr Yiasoumi: "Come on, preparing a Plan B for events that are unlikely to happen, surely it is a waste of time?" Rhian (Littlewood), would you like to answer that one?

Ms Littlewood: I am with Dweenisha (Caleechurn) there. I do not think you can live through this year without seeing some value in having a Plan B. There is so much that could change at short notice. We heard earlier about the importance of covenant, for example, and the fact that you might think you have many, many years to get there, but if your employer's covenant weakens suddenly, that might change. You need a Plan B to avoid making decisions in a rush or in a difficult situation, to avoid suboptimal decision-making.

Mr Yiasoumi: Yes, and if you have a Plan B, it may even impact how you implement your Plan A. You may have a Plan A, but the way you deal with it might end up jeopardising or making your Plan B more difficult. Again, that brings a level of a trade-off for the trustees.

Let's move on to the next poll, on member outcomes.

Poll 2

Actuaries should champion the common use of member outcomes analytics to assist client decision-making.

Results of Poll 2

\begin{tabular}{lc} 
Strongly Agree & $22 \%(34)$ \\
\hline Agree & $63 \%(99)$ \\
\hline Disagree & $14 \%(22)$ \\
\hline Strongly Disagree & $1 \%(1)$ \\
\hline & Total votes 156 \\
\hline
\end{tabular}

Kevin (Wesbroom), you were quite keen on member outcomes as a working party member. Only 15\% disagree with you. You must be quite pleased with this?

Mr Wesbroom: Yes, that is good to see. However, there have been quite a few questions coming in, pointing out some of the practical difficulties here. In my $95 \%$ example, does that mean each 
member always gets $95 \%$ of their benefits, or do they only get their benefits $95 \%$ of the time and $5 \%$ of the time they get something horrible?

Mr Yiasoumi: We need a common definition, don't we? We cannot be talking at crosspurposes in the industry on those sorts of matters.

Mr Wesbroom: Yes, that's a very good point. We need to get to some consistency and commonality so that we can genuinely help not just the decision-makers, but potentially even members, when we start publishing this to members. That would be quite a scary thought.

Mr Yiasoumi: Let's move to the next poll.

Poll 2 (cont.)

Schemes should develop and understand their Plan B in the event of employer distress or insolvency (a scheme in a comfortable position today might be a stressed scheme tomorrow!).

Results of Poll 2 (cont.)

Table 4.

\begin{tabular}{lc}
\hline Strongly Agree - essential for all schemes other than the smallest & $42 \%(70)$ \\
\hline Agree - every large scheme should do this & $44 \%(73)$ \\
\hline Disagree - we already know the answer is usually PPF entry or PPF buyout & $12 \%(21)$ \\
\hline Strongly Disagree - sounds like yet a further burden for already busy trustees & $2 \%(3)$ \\
\hline
\end{tabular}

What do you think? Adolfo (Aponte) would you like to comment on this? There are a lot of people who strongly agree, which surprises me. Adolfo (Aponte) are you happy with this result?

Mr Aponte: I think this is a response, in part, to TPR's increased focus on ongoing planning. If you had run a similar poll a few years ago, when covenant was not thought through as a key driver of end game decisions, the results might have been different. As the industry matures, along with pensions regulation, I am not surprised at all by these results. If anything, it just presses the point that we need to make sure our trustee clients understand the importance of this factor.

Mr Yiasoumi: That's great. Having a fallback is just common sense. On the topic of Plan Bs, let's move on to stressed schemes. We have spoken about Plan B, but to develop a Plan B, we need to be aware of the issues in running a scheme that has a high likelihood of never making it. By being aware of those issues and rehearsing the what-ifs schemes can be quite well versed in their options. Nigel (Jones), what is a stressed scheme?

\author{
Stressed schemes - crisis, or well drilled scenario? \\ 1. Stressed Schemes whose funding \\ level is well below $100 \%$ against PPF \\ 2. Stressed Schemes whose funding \\ level is around $100 \%$ or better against \\ PPF \\ 3. Scheme(s) Without a Substantive \\ Sponsor ("SWOSS")


Mr Jones: There are several things to consider. Essentially, a stressed scheme is one that is underfunded and has a high likelihood of employer failure. That is the difficulty. There is a benefit for trustees and in turn members to keeping schemes going, because keeping a scheme going gives you shorter exposure to the PPF, and that will ultimately improve the member outcome.

Mr Yiasoumi: Jane (Kola), can you please tell us about PPF drift?

Ms Kola: I think the audience probably has more experience of calculating PPF drift than I will ever have, but it is the increase in the cost of liabilities to PPF as members retire. The more people get to the pension age, the more it will cost for the PPF to cover those benefits, because the compensation is higher, or can be. That is an important question for the PPF and the pensions regulator, although I am not sure it is necessarily that important a question for trustees once they are outside the possibility of ever going into the PPF because they are better funded than that. Nonetheless, it does come up for schemes funded below PPF level of liabilities.

Mr Yiasoumi: So, to build on the point and where Nigel (Jones) was going, what you are saying is that for a scheme that is under $100 \%$ funded on the PPF, members' interests are enhanced if the sponsor remains solvent so the scheme can just keep running, even if the sponsor is in a dwindled state. You have to buy time.

Ms Kola: Yes. The PPF and TPR may not be keen on that situation, but it is not gaming the PPF for a scheme to just continue as it always has and its sponsor to struggle on. Gaming the PPF is different; there is no obligation on the part of trustees to treat the Pension Protection Fund as a beneficiary in respect of their scheme, but they absolutely have to look after the interests of the members of their scheme. Time can improve the member position as long as the Trustees are not propping up their employer in an artificial way.

Mr Yiasoumi: That is a question that I will come back to in a moment about legal structures in this area, because I think it is connected with Schemes Without a Substantive Sponsor (SWOSS)s. Nigel (Jones), what is a SWOSS?

Mr Jones: As you say, SWOSS is a scheme without a sponsor. The covenant has almost disappeared, and the scheme is relying on what is left. A SWOSS continuing to run in a closed state will have the benefit of some form of funding level that is above the PPF level of benefit, and the trustees of the SWOSS can decide what to do with that. Whether the scheme is a SWOSS or an ongoing scheme, as the funding level increases they will have options to push up the expected value of the member outcome, whether through reshaping benefits, member options or superfunds or buyouts. All that hinges on the level of funding. It has to be at a reasonable base level.

Mr Yiasoumi: In effect, if the sponsor becomes insolvent, you would normally have a PPF assessment process and the scheme will either end up in the PPF if it is not well funded, or if it is quite well funded, you would have a PPF plus buyout. What we are saying here is that for schemes that are sufficiently large and have a decent funding level, they could possibly arrange their affairs so that even if the normal sponsor becomes insolvent, they can continue running.

Jane (Kola), what else should trustees be considering on legal structures that become SWOSS?

Ms Kola: The trustees do often have the ability to do this with the help of their sponsor. The question is whether it is in their members' interest to do so. For some schemes, the trustees may well take the view that it is in the members' interest to buy that extra bit of time. They might be so close to buyout and feel that they have the sophistication to get to buyout without their sponsor, that they do put a blocker in to prevent that PPF plus buyout. The other scenario I have seen is where there is other covenant elsewhere in the world, but it is not willing to be associated with the scheme directly, in which case a SWOSS approach can be a way of getting more money in, which the scheme otherwise would not get in an insolvency situation, and that also gives a good reason to do it. However, I do not think trustees should put these structures in place lightly. They have to be completely satisfied they are in the interest of their members in what is a very difficult situation to operate in.

Mr Jones: Yes, it is a difficult position to be in. The other fact is the efficiency of capital. With the introduction of superfunds and those other solutions, you may be able to use capital more 
efficiently, and that definitely gives trustees thoughts on whether to proceed on a SWOSS route. That could be more efficient.

Mr Yiasoumi: That efficiency point links into low-dependency because, if you reach a lowdependency state, that means you expect to be able to run off the scheme with minimal or no reliance on the sponsor, but you still have a legal reliance. As Adolfo (Aponte) said earlier, the sponsor buys you time. So, it seems to me that this might be intricately linked to a more robust form of low dependency. You would not want your employer insolvency to call time when you could otherwise have run the scheme off, meeting benefits in full because you have your investments and longevity hedged and funding in a good place. Adolfo (Aponte), is this part of Plan B planning?

Mr Aponte: It certainly should be. As we look at the various risks that a scheme faces - interestrate risk, inflation risk, longevity risk - we find that there are tools out there to allow us to hedge those risk factors completely or partially. But when it comes to covenant, there are very few options that are in the trustees' control to hedge your exposure to the covenant. As we have noted before, that is relevant for most schemes regardless of their funding level. We should recognise that, up to now, the industry has managed covenant risk as something that is completely out of control of the trustees. However, as a working group, we are highlighting that there are schemes can have more control over their destiny and then should get proper legal advice and advice from various stakeholders and engage with the regulators on this issue. This may well be an option for them.

Mr Yiasoumi: The chapter on stressed schemes that we drafted was revised quite substantially. It was really helpful to get feedback from TPR, PPF and The Department for Work and Pensions (DWP) on the paper. What are TPR's and PPF's expectations here?

Mr Aponte: Good question. As you say, we have gone through a journey on that chapter. We started the chapter requesting additional guidance for all schemes in this area. Ultimately, we recognised the point that Jane (Kola) has highlighted. Whilst trustees cannot game the PPF, they are not there to protect the position of the PPF. That leaves trustees in a slightly awkward position. From our engagement with the PPF, TPR and DWP, it was clear that they had been giving this aspect some thought. They pointed us in the direction of the latest superfund guidance, which notes that employers or Special-Purpose Vehicle (SPV)-like employers in this position should engage with their legal advisor and with TPR before putting these actions in place. I think it is an area that they are looking at further developing and communicating with the industry on, given its relevance to some of the schemes.

Mr Yiasoumi: I cannot speak for TPR, but I am sure they won't want thousands of SWOSS floating around. But for well-funded pensions that are well run and have locked down the risks and that have got the economies of scale, this may certainly improve member outcomes materially. It is definitely something, as an industry, we should spend more time on. Let us move on to our final poll. We have spoken about various facets of our paper. One thing that has come through is that the actuary and the profession can be at the centre of this.

Poll 3

The future role of the actuary will be pivotal in helping trustees to understand how to bring together the necessary funding, investment and covenant considerations as well as helping include legal and operational considerations. In that role, the actuary would work closely with other specialist advisers.

Results of Poll 3

Strongly Agree - actuaries are perfectly and probably best placed

Agree - but other professionals can also do this equally well

Disagree - other professionals are better placed

Strongly Disagree - this does not require actuarial skills
$48 \%(73)$

$48 \%(72)$

$3 \%(5)$

$1 \%(1)$

Total votes 151 
Dan (Mikulskis), do you want to comment on this? It is a very strong consensus that actuaries are well placed here.

Mr Mikulskis: Yes, a hugely surprising result here! Actuaries feel they are brilliantly placed for this sort of role. But it was worth saying that explicitly in the paper. This is actually quite a different role. It is all very well to say that actuaries are well placed because they are in the middle of things, but this is about strategic thinking. It is about being a decision-making coach. It is not about calculating numbers to five decimal places any more or defending specific sets of assumptions or discount rates. It is actually quite a big shift and that is something that people can hopefully start to internalise and then take forward.

Mr Yiasoumi: The final slide is a summary of the eight recommendations. Leah (Evans), I will hand the reins back to you so as to address some of the questions.

\section{Summary of our eight recommendations}

\footnotetext{
- Actuaries should press trustee boards to take legal advice on their powers and on members' legal entitlements.

2. Schemes should define clearly what their TES
means in practice, not adopt sanguine definitions.

3. The profession should sponsor research into the use of dynamic discount rates for technical provisions.

4. Strategy and journey plan is sometimes driven by an employer's financial statements. This can be sub-optimal to Member Outcomes. This is an area for further work by the profession and by TPR.
}

\begin{abstract}
Schemes should develop and understand their Plan B in the event of employer distress or employer insolvency.
\end{abstract} 6. We recommend actuaries help clients focus
on Member Outcomes.

\footnotetext{
Member Outcomes analysis is very dependent on assumptions and models. The actuarial profession should sponsor research into this area.

There is a need for clear and consistent legislation and/or detailed guidance on running a scheme as a SWOSS in the event of sponsor failure.
}

The Moderator: Thank you all for a really good discussion. One theme that has been coming up a lot is the assumptions and the models. I personally agree that looking at member outcomes is a really useful and valuable addition to what we do, and more relevant than just looking at funding level. But as we have seen from the comments, there are clearly a lot of issues around the assumptions and parameters used for modelling. What is the interaction between contributions and employer failure? Do we risk trying to over-engineer something that then ends up being so reliant on assumptions that it isn't actually that much more worthwhile than what we do already?

Mr Milkulskis: That is a really good question. I come back to the famous quote that "all models are wrong, but some are useful." The aim here is not to be right, but to be useful. To the extent that the modelling outputs are useful, it is worth doing. It is not about arguing when they are right or wrong. In terms of the assumptions, of course, modelling outcomes will be sensitive to a whole range of assumptions. One thing I think we felt that the profession could do was to have a voice in what reasonable ranges are for those assumptions and act as a clearing house for different sets of assumptions. This way, consumers of that modelling can test the assumptions their advisors have used against something that is deemed to be reasonable.

Mr Wesbroom: That is a good point, Dan (Mikulskis). You could even take that to its logical conclusion: why don't we ask TPR to set the modelling assumptions that should be used to predict member outcomes? Let's reinvent the Minimum Funding Requirement (MFR) through the back door! One of the things on the chat that has come up is the question of long-term covenant modelling, perhaps not surprisingly. I am paraphrasing slightly, but actuaries are saying, "covenant advisors, can you do your projections as well as we can do ours?" 
Mr Aponte: That is a very good point. The reality is, and TPR has picked up on this, the exposure a pension scheme has to its covenant is usually to a single name, to a single creditor. It is not to a portfolio of corporate bonds, which is where you can use probabilities of default to drive results. However, I go back to the response from Dan (Mikulskis). Ultimately, we are trying to help our clients weigh different options. So even it if the model is not completely accurate, it should help stakeholders understand the underlying drivers. As we have pointed out through this conversation already, there are some counter-intuitive aspects that the industry has not faced directly, which we could definitely do more of.

The Moderator: As a follow-on from that point on assumptions, another theme that has come up is the size of the scheme. To what extent are solutions like full buyout possible for the smaller schemes? Secondly, for the smaller schemes, there is probably a discussion to be had around how much time to spend on modelling. And a third point is that idiosyncratic risk is also very important. How do you suggest that smaller schemes address these? Is there anything they should be doing differently?

Mr Yiasoumi: For smaller schemes, there is definitely a challenge in terms of what Target EndStates might be in play. Although there are some consolidation-type options out there that give access to big-scheme solutions, for smaller schemes, they can only go so far. Options like fiduciary management and DB master trusts, say, all help. But realistically, especially once you allow for the expenses of running a scheme, the only end game may be either buyout or transfer to a superfund, with the Plan B planning being around what happens if the employer defaults, and this would be either PPF entry or a PPF plus buyout. But member outcomes can still be modelled for a smaller scheme; I do not think that is an issue. It is just that you can potentially have more volatility in how that unfolds in the future because a small scheme inherently has more volatility in its funding level. And there is a sense of proportionality in all of this.

Mr Wesbroom: You mentioned a couple of examples, Costas (Yiasoumi), where as an industry we have taken concepts and descaled or downscaled them so that they can be applied more widely - ideas like fiduciary management and liability management exercises. We have a reasonable track record of making solutions downwardly scalable, but it will be a challenge to get access to some of the new thinking. It may be that it is only through those consolidation vehicles that small schemes get genuine access to the best thinking in this area.

The Moderator: There is a question for Jane (Kola) by Rob Evans. If a scheme was able to get to full buyout, but then decided to continue to run off, could the trustees be criticised for that?

Ms Kola: It would depend on the reasons why the trustees were doing that, and it is also very rule-specific. Generally, the majority would see their objective as securing full benefits as best they can within an insurance market because that is currently, as we see it, the safest place to be. There are schemes that have rules that mean the trustees could justify carrying on. However, I do not think the majority are in a position where they can justify trying to carry on and trying, perhaps, to get surplus for improvements rather than just buy the benefits that people are entitled to. I think those schemes are few and far between. There may be circumstances where it is possible to run on past buyout level funding, but in most cases, I suspect, trustees would find it difficult to justify doing so and not buying out.

The Moderator: Thank you. We had a question in the chat mentioning that the solvency position of the scheme is only a side issue and the funding position is the one that is taken note of. Can the regulator do something here to raise the profile of the solvency position? There is probably a question as to whether we would want the regulator to do that or, more generally, do you think the regulator should be doing more on the various things that you have been doing? Do you think we need any additional legislation?

Mr Yiasoumi: There are some areas we have highlighted where we think it would help to have more of, for example, in the area of SWOSS. It just seems to be a twilight zone with some schemes looking at it and some not, and quite often it is driven by the trustees' or the board's appetite to go 
that extra mile for the members. That is one I would definitely highlight, because it just feeds so much into the Plan B, especially for larger schemes.

Ms Kola: TPR could help everybody by pointing out that trustees do need to understand what benefits they are supposed to be paying. They do not tend to say that very often. They talk about data. They do not talk about entitlement. I think it would be good for all of us if TPR were clearer that it is not just the data that matters.

The Moderator: Great. Thank you very much for the discussion. Thank you to all of the team who presented and thank you very much to everyone who participated in the chat. It has been very interactive and great to see so much involvement. Thank you for joining in and please do follow up with us with any further questions.

\section{Additional Q\&A}

Question and answer 1. Stochastic modelling is great for large schemes, but is beyond the budget of most small schemes. Furthermore, in small schemes, random variations in experience are far more significant.

Two separate but very valid points. We will need to work though how to downscale this type of analysis and develop solutions to deal with idiosyncratic risks.

Q\&A 2. How reliable are stochastic models at modelling tail probabilities on long-term horizons? Surely we have not had enough history to model beyond 20 years with any reliability. Won't the results depend a lot on how the stochastic model has been calibrated and be highly subjective?

Agreed. We do not want to get into a position where one outcome is believed to be superior, simply because of the quirks (or otherwise) of the modelling assumptions. All models are wrong, but some are useful. The aim is not perfect modelling, but to produce something that is useful for decisions. Model outcomes that would inform a decision that increases probability of meeting all liabilities from $80 \%$ to $90 \%$, for example, would be useful to know; from $95.5 \%$ to $95.6 \%$, not so much.

Q\&A 3. For schemes where the funding level sits somewhere between $100 \%$ PPF and $100 \%$ full member benefits, trustees need to pay more regard to PPF drift and how this creates winners or losers across different classes of member. Do you agree that actuaries need to do more to help trustees understand this better?

Yes, this is a really important area. All parties, including PPF, need to recognise that it is legitimate to consider how funding drift informs the strategic direction of a scheme and this analysis is not the same as gaming the PPF.

Q\&A 4. Insurers use something like a dynamic discount rate through the matching adjustment. Is there merit to learning from the experience of the insurance regime?

One of our key recommendations is that the profession sponsor some research into methodologies for dynamic discount rates for pension schemes. An issue is that insurers usually employ large teams of actuaries to develop and calculate their reserves and capital, including dynamic discount rates. Pension schemes do not have that resource, so something more off the shelf but still robust would be necessary. Most of the pensions industry operates on a "gilt +" approach, so a challenge for pension schemes is to rationalise why a dynamic discount rate is preferred, for example, to TPR.

Q\&A 5. A key point with PPF drift is that, from the standpoint of members with deferred benefits, it can often be worse to continue the scheme than to trigger wind-up. Actuaries are well-placed to help trustees weigh up the options here.

Yes. This is an intergenerational issue that often receives insufficient attention. From a trustee perspective only, PPF drift becomes important once a scheme is funded above the level of the PPF liabilities. Retirement can have a large impact on the recovery of deferreds if the scheme goes into 
winding-up without full funding, and actuaries are well-placed to model such impacts. However, there is more to this than just the likely member outcomes of continuing versus winding-up, which means that both legal and covenant advice are a key part of the monitoring process. Generally, trustees do not have a free-standing legal right to terminate a pension scheme and cause a winding-up to start. Even if PPF drift is causing intergenerational concerns, that does not mean that trustees are able to do anything about it. Where trustees do have powers that would permit them to trigger a termination and winding-up of the scheme, the trustees should recognise and consider using them. One should also not underestimate how challenging such a decision would be and, at a minimum, trustees would need detailed advice on their legal powers and duties, covenant advice on the sponsor's genuine chances of survival and actuarial analysis of the member outcomes and impact of PPF draft. This is a multifaceted issue that is likely to become more prevalent, and will need careful consideration by those schemes affected.

Q\&A 6. What is the difference between dynamic discount rate and deriving a discount rate based on the actual yield of the existing assets?

Very little when focusing on secure income assets such as corporate credit. The dynamic discount rate would be net of various adjustments such as allowances for default and downgrade.

Q\&A 7. It is worth noting that PPF compensation isn't “secured". Payment level is dependent on PPF performance, which is very sensitive to big insolvencies.

I agree. I do think it might be similar to the question of whether insurance is $100 \%$ secure. We could construct scenarios where an insurer fails and members get less than the insured benefits. However, this is very unlikely. Equally, the PPF could "fail" and members could get less than expected compensation - again, hopefully this is unlikely, but perhaps there is more scope for compensation reduction here?

Q\&A 8. On your member outcome models, have you been very careful in the modelling to reflect the fact that the stochastic model and mean and volatility parameters for equities reflect the short-term nature of the projection? For example, to reflect the fact that we are not looking at a 25-year period, but a risk transfer in around 10 years.

Yes, this is a very important point on the time horizon, and we have modelled as such.

Q\&A 9. From bitter experience, I think there would be a real benefit to all DB schemes having a full benefit specification reviewed by the scheme's lawyer to ensure the scheme is calculating and paying benefits in accordance with the legal documents. The scheme administrator should confirm compliance annually.

This is an excellent idea and something that all schemes should work towards. The legal duty is to pay the right benefits to the right people at the right time under the terms of the scheme rules, not to pay what has been set up on the administration system. Trustees have traditionally been reluctant to invest in a legal review of what is paid against the rules, either because they fear that legal issues will be found, or they operate in the mistaken belief that administration take-on processes capture both legal and data issues when they do not. There is no such thing as a perfectly run scheme with perfect data and calculation processes that perfectly match the rules. There will be gaps, ambiguities and issues. Those exist whether trustees do a legal review or not. However, trustees who do the legal review work are investing in their journey plan, and are making informed and risks-based decisions about those gaps, ambiguities and issues so that they stand a much better chance of reaching their target end state efficiently and effectively.

Q\&A 10. Isn't the task discussed in poll 1 (pressing trustee boards to take legal advice on their powers under scheme rules and on the detailed benefit entitlements of members) the job of the scheme lawyer?

The lawyer is often not in the room. Therefore, it is important that the actuary advocates for a legally signed-off benefit specification and a balance of powers summary. 
Q\&A 11. I agree that Trustees should focus more clearly on expected member outcomes when deciding on their TES. Do the authors believe that some form of member outcome analysis should be shared with members (who may be surprised at the results!)?

Most definitely, but we do have to be able to put this in context. If we tell members that they are 95\% likely to get their benefits, should they be happy or scared? Will they look to transfer out their DB benefits - which may not be the right thing to do? The typical member will not understand probability-based outcomes, nor indeed may the more financially-aware IFA community. Full disclosure is obviously important, but we are likely to need new industry advice standards. In an ideal world, we might envisage an industry-standard definition on Member Outcomes that we can share widely.

Q\&A 12. Poll Q2 (research into dynamic discount rates) - I agree with the rationale for dynamic, asset-led discount rates, but am not convinced of the need for the Profession to sponsor research in this area. It is something that we have been looking into for some time, as the assets will never deliver "Gilts + fixed", so the fixed approach just leads to funding volatility. What do you envisage the proposed research would look into?

Yes, we agree that the dynamic discount rate will help to remove funding volatility that is artificial in nature, especially as schemes increasingly adopt low-dependency Target End States (TES). We feel that low dependency TES has not been subject to the level of research and innovation that other areas have. This research should therefore build the case for smoother funded positions through time and less variability in deficit-reduction contributions. It should look at how investment and funding policies need to work together to deliver the best Member Outcomes and develop methodologies for variable discount rates to better align funding measures with financing, which the industry can then adopt.

Q\&A 13. We need to be careful with PPP. A higher-risk investment strategy will automatically result in a higher PPP for a given scheme, and higher assumed probability of default. Looking at a lower-risk strategy in isolation is not realistic, as it will typically be combined with higher contributions from the employer.

That is correct assuming that the probability of default is not changed. However, looking at the range of outcomes for PPP, such as the $90 \%$ confidence interval, may show some illuminating impacts. For example, the downside scenarios for a higher-risk investment strategy may not be palatable for some member groups or, indeed, there may be a floor due to PPF protection. (I understand that trustees cannot take into account the existence of the PPF in decision-making, but that is an issue for the lawyers.)

Q\&A 14. The PRA has already hinted about changes in relation to future annuity reserving, but this is unlikely to cause a jump in pricing.

Agreed. The Risk Margin review may improve flexibility around treatment of longevity risk, but there are no immediate signs of a step change in pricing.

Q\&A 15. Would a Merger and Acquisition (M\&A) transaction be a good Target End-State? This might result in a material DB scheme obtaining a much stronger covenant.

That would be a nice option if you could get it. However, you would still have to face the issue of what to do from the new position - for example buyout or low dependency. A consolidator may be off the cards if the new covenant really is strong.

Q\&A 16. One risk that has recently come into focus is past transfer values (TVs) and Guaranteed Minimum Pension (GMP) Equalisation. Given the onus on trustees to be proactive, but the expected lack of means of correcting and/or tracing the member, is there an insurance solution? Run-off insurers do not like this risk, but in most cases claims will be rare.

An insurance solution could be developed. However, there would be the usual price friction as bespoke insurance solutions come at perceived high premiums. Trustees may still be best placed for seeking internal solutions as part of their buyout-ready governance rather than relying on insurance solutions, especially given that most volumes are likely to be low. 
Q\&A 17. The press article today says actuaries should be "strategic advisers". Does the group think that others can equally do this task (lawyer, trustee, etc.)?

Definitely. We are stressing the multi-disciplinary nature of the challenge of End Games, and actuaries need to prove the value they add, rather than assume that they have the key seat at the table.

Q\&A 18. Given that buyout was mentioned as the "best" solution, what proportion of the

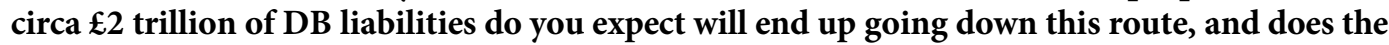
insurance industry have the capacity for this?

We have seen various surveys that indicate a third or more of schemes have buyout as their long-term target. The insurance industry as a whole has access to a deep pool of capital, and we have seen capacity increasing as volumes increase over the last few years.

Q\&A 19. What proportion of PPF-eligible DB members are now under age 50 with significant pre-1997 accrual, who might be significant losers from PPF entry?

The proportions will vary by scheme. The characteristics of members who lose the most on PPF entry include deferred pensioners with high levels of pre-1997 indexation in payment, or with high fixed rate revaluation on GMP's pre-retirement. Contingent spouses of pensioners can also be big losers, as the PPF calculates spouse pensions as a proportion of post-commutation pension rather than pre-commutation pension. The key point is that most trustee boards do not have analysis to hand that shows them how different member groups would be impacted by employer insolvency aggregate funding levels are inadequate for this purpose. Consequently, they cannot feed that into decision-making in areas such as investment strategy, risk hedging and deficit reduction funding.

Q\&A 20. Perhaps a question for Jane (Kola). If a scheme were to achieve full funding on a buyout level of funding, could the trustees be criticised for not buying out and instead running on?

In most schemes, there is no obligation to invest in buy-in policies to match the liabilities, and most trustees cannot achieve buyout alone as they do not have the power to trigger a winding-up. However, most trustees who hold sufficient funds to secure a full buy-in policy with a reputable insurer that matches the liabilities are likely to use their power of investment to de-risk completely rather than rely on the sponsor covenant. Most trustees are likely to find that their sponsor is on board with such a view. However, there will be cases where trustees may feel justified to run on and not enter into buy-in policies. These include situations where the covenant is strong, there is no appetite from the sponsor to buy in, and/or the trustees can yield benefits for members from surpluses worth the risk of continuing (this does not mean that trustees should invest for surplus. However, there are a small number of schemes where the rules permit this and this is something those trustees should take account of.) At the end of the day, this is value judgement between the risk of running on and being unable, at a future date, to buy in full legal entitlements against the possibility of greater benefits for members. Most trustees will not take the risk of running on, but that does not mean that no trustees can ever make that decision or that such a decision would automatically attract criticism.

Q\&A 21. A non-insurance Plan B is very important if your scheme's insurance journey plan is beyond covenant visibility (and in most cases it will be).

History tells us that a significant proportion of employers will not be around in 10 years, and the pace of innovation is only increasing. Schemes need to have a Plan B that responds to this scenario. After all, the failure of an employer is the event that usually triggers a permanent loss in benefits for members. Trustees that have developed robust contingency plans will recognise that there are a number of steps that can be taken well in advance of any insolvency event. It is also likely that new end-game solutions have a role to play in these plans.

Q\&A 22. Could the IFoA work towards a prescribed approach for calculating a broadly accurate key performance indicator (KPI) for member outcomes?

Yes. Ideally, we would have the IFoA as a clearing house for reasonable assumptions. It is hard to come up with a single correct set of assumptions, but a guide to reasonableness would be helpful to avoid firms skewing analysis. 
Q\&A 23. The powerful part of the member outcome modelling is when you allow for the scheme and sponsor interacting. A lower risk strategy may lead to higher contributions (so more money in the short term), but in turn increase the risk of sponsor insolvency.

Exactly - and these are the types of questions that have often been shied away from.

Q\&A 24. There are a lot of similarities between this topic and that of with-profits run-off plans, but the implication appears to be that pensions benefits do not need to be as secure as insurance. Can the rest of the market survive if that results in some high-profile cases of members receiving less than promised benefits?

That is a fair point. I would observe that the market has survived - so far - with some members receiving less than promised benefits. They, at least, get PPF benefits as a minimum. The question is, will we continue to accept that is enough?

Q\&A 25. Very mature schemes are already reducing their risk to the sponsor (by definition, they are reducing in size). As such, are we really saying that all schemes need to be focused on de-risking the investment strategy in addition to this? Any open schemes left will be closing as a result...

We are not advocating de-risking for all. We are advocating a framework where trustees, sponsors and regulators can understand the consequences of de-risking or not.

Q\&A 26. Why might a scheme offer a higher transfer value but a lower commutation value than an insurer?

This is due to the difference between the pensions regime and the insurance regime in relation to member options.

Q\&A 27. Did the working group consider conflicts of interest? For example, pensions actuaries will be out of work if all schemes go to buyout, and some options require much more actuarial input than others.

No, we didn't consider this. We also need to think about potential conflicts with other groups investment advisers, covenant advisers and possibly others with valid inputs to end-game planning.

Q\&A 28. On the issue of whether $95 \%$ means each member always gets $95 \%$ of their benefits, or only get their benefits $95 \%$ of the time, the $95 \%$ could also be due to a lack of inflationary increases.

Good point. In the paper we made the point that members may place a very different value on future increases to what we would place as actuaries. This may point to including some behavioural finance aspects to Member Outcomes, or a need to overlay utility functions.

Q\&A 29. I have come across sponsors who are markedly more risk-averse in areas of member benefits than their trustees. However, I am not sure many sponsors have good visibility of those risks.

The new Pensions Bill might focus the minds of CFOs. It is certainly having an impact on the willingness of corporate non-executive directors to engage with DB pensions. Advisers play an important role in ensuring that CFOs and their Boards have the information they need to input into the trustees' strategic thinking.

Q\&A 30. How practical or realistic do you see your proposal as being for smaller schemes, given the significant cost implications and uncertainties around these detailed and complex models? How much should Trustees spend?

As a trustee, I would take a proportionate approach.

Q\&A 31. Does the dynamic discount rate also work to reduce volatility with equity investment? The floating component becomes linked to dividend yield (plus real growth).

Dynamic discount rates are referred to in the context of secure income assets such as corporate credit. Bringing in equities would be a challenge ... and would take us back to the discounted dividend models used for asset valuations $20+$ years ago. 
Q\&A 32. If employer affordability is an overriding constraint, then higher employer contributions aren't an option.

If employer affordability is an over-riding constraint, can you afford to take higher risk?

Can you afford not to? If funding levels are below PPF, there would be no downside impact on members' benefits. I know we are not supposed to allow for the PPF, but the only possibility for getting PPF+ benefits for members is taking some investment risk.

There are two important points here. Affordability, the ability of an employer to make deficit contributions, can be volatile, dipping into negative territory during a normal business cycle. If affordability is constrained, trustees will want to understand if the dynamic is likely to persist over the medium term.

Where affordability and visibility are low, trustees need to think carefully about their options as the trade-offs will be more pronounced. It may be possible to increase investment risk with the aim of improving the funding position over time, but who would be underwriting the increased risk? It is likely to be the deferreds and/or the PPF. Trustees do not have a duty to protect the PPF (leave that task to TPR) but they should not game the protection it provides to the industry. Legal advice can play a very important role in ensuring trustees (and advisers) stay on the right side of the line when it comes to these decisions.

Q\&A 33. There could be more focus on the sponsoring employer's perspective rather than the trustees. In my experience, the last thing a sponsor wants is uncertainty. Data, legal and GMP risk are classic examples. I am surprised that more employers do not go for certainty through deferred premium structures.

Agreed. We often see employers pushing for as much cost certainty as is achievable. Deferred premium structures may not be available to all schemes, depending on the level of competition in the market and the quality of the scheme's data, so there is a trade-off.

Q\&A 34. Currently, it feels as if the solvency position of a scheme is only a side issue, and the funding position is the only one that is taken note of. Can the regulator do something here to raise the profile of the solvency position?

See the revised Funding Code that TPR is currently consulting on! With the new DB Funding Code and Pension Scheme Act 2021, the long term objective is now going to be a very important consideration. Trustees will now need to articulate clearly their end-game journey and how they intend to reach there. This will put the solvency position back in focus. It is positive to see the solvency position moving higher up the agenda, and this feels like a natural progression in line with the materially improved average funding position of schemes over the last 10 years. The thinking feels "too new" for member input at the moment, but one would expect this to develop over time.

Q\&A 35. Some actuaries already present one-time and projected solvency positions, and impacts on member benefit entitlements in case of wind-up at different points in time.

Yes, some actuaries do carry out a lot of stochastic modelling around solvency positions to project over different time horizons. As we know, one of the main issues with the solvency position is that it has not always accurately reflected the true cost of buying out the benefits - it has not been an exact science. The true cost of buying out a scheme can only be known by going to market, but these projections do help to get a general sense of how close or how far a scheme is to a buyout.

Cite this article: To the End Game and Beyond: [Institute and Faculty of Actuaries, Sessional Webinar, Monday 11 January 2021]. British Actuarial Journal. https://doi.org/10.1017/S1357321721000088 